\title{
ANALISIS SUMBER DAN PENGGUNAAN MODAL KERJA PADA PT. INDOFOOD CBP SUKSES MAKMUR TbK
}

\author{
Deki Pardana \\ Program Studi Manajemen, Fakultas Ekonomi \\ Universitas Muhammadiyah Buton, Baubau, Indonesia \\ Email :Dekiperdana81@gmail.com
}

\begin{abstract}
ABSTRAK
Penelitian ini bertujuan untuk untuk menganalsis sumber dan penggunaan modal kerja pada PT. Indofood CBP Sukses Makmur Tbk. Metode analisis data menggunakan metode kuantitatif. Metode pengumpulan data menggunakan metode dokumentasi. Hasil penelitian menunjukkan bahwa Secara umum sumber dan penggunaan modal kerja pada PT. Indofood CBP Sukses Makmur Tbk untuk periode 2015 sampai dengan 2016 sudah efesien. Sumber modal kerja yang merupakan tulang punggung operasi perusahaan selalu tersedia dan mengalami kenaikan dari tahun sebelumnya, sehingga kebijakan perusahaan khususnya yang berkaitan dengan operasionalisasi guna mendapatan laba (profitabilitas) dapat dicapai. Kebijakan penggunaan modal kerja dapat dikatakan sesuai dengan sasaran manajemen.Melaui pengadaan kewajiban perusahaan sebagai salah satu sumber modal kerja perusahaan, PT. Indofood CBP Sukses Makmur Tbk mampu menggunakan sumber modal tersebut dengan efisien sehingga mampu menghasilkan kekayaan dalam bentuk aktiva yang berguna bagi jalannya aktivitas bisnis perusahaan selama tahun 2016.
\end{abstract}

Kata kunci: Modal Kerja, Sumber Modal Kerja, Penggunaan Modal Kerja.

\section{ABSTRACT}

This study aims to analyze the source and use of working capital at PT. Indofood CBP Sukses Makmur Tbk. Data analysis using quantitative methods. Data collection using the documentation methods. The results showed that in general the source and usage of working capital at PT. Indofood CBP Sukses Makmur Tbk for the period 2015 until 2016 is efficient. The source of working capital which is the backbone of the company's operations is always available and has increased from the previous year, so company policy especially related to operationalization in order to get the optimal profit (profitability) can be achieved. The policy on the use of working capital can be said in accordance with the objectives of management. Through the procurement of corporate liabilities as one source of working capital of the company, PT. Indofood CBP Sukses Makmur Tbk is able to use the capital resources efficiently so as to generate wealth in the form of assets that are useful for the business activities of the company during the year 2016.

Key words: Working capital, source of working capital, usage of working capital

\section{PENDAHULUAN}

Dari sudut manajemen keuangan, keberhasilan perusahaan dapat dinilai dari tiga macam kinerja bisnis yaitu profitabilitas, solvabilitas, dan likuiditas. Seberapa jauh keberhasilan perusahaan mencapai ketiga kinerja bisnis tersebut, secara memuaskan 
dapat diukur dengan tolak ukur keuangan yang disebut rasio keuangan. Khusus dalam kinerja keuangan seorang manajer harus mengetahui dan mempertimbangkan secara cermat sumber-sumber mana yang paling menguntungkan apakah modal sendiri, modal pinjaman, atau kombinasi dari keduanya [1]. Manajemen keuangan sebagai atau sering disebut pembelanjaan dapat diartikan sebagai semua aktivitas perusahaan yang berhubungan dengan usaha-usaha mendapatkan dana perusahaan dengan biaya yang murah serta usaha untuk menggunakan dan mengalokasikan dana tersebut secara efisien [2].

Tujuan dari manajemen keuangan itu sendiri harus melalui dua pendekatan dalam mencapai tujuannya, yaitu: Profit risk approach, dalam hal ini berkaitan dengan seorang manajer tidak sekedar mengejar maksimalisasi profit, akan tetapi juga harus mempertimbangkan resiko yang bakal dihadapi serta harus terus melakukan pengawasan dan pengendalian terhadap seluruh aktivitas yang dijalankan dengan menggunakan prinsip kehati-hatian. Liquidity and profitability, merupakan kegiatan yang berhubungan dengan bagaimana seorang manajer keuangan mengelola likuiditas dan profitabilitas perusahaan [3].

Modal kerja adalah investasi perusahaan dalam aktiva jangka pendek atau lancar, termasuk dalamnya kas, sekuritas, piutang, persediaan, dan dalam beberapa perusahaan, biaya dibayar di muka [4]. Modal kerja ialah modal secara kolektif mencakup aktiva dan pasiva lancar atau jangka pendek, sedangkan modal kerja netto mencerminkan perbedaan antara aktiva lancar dan pasiva lancar perusahaan [5].

.Berkaitan dengan pengertian modal kerja ini dapat dikemukakan beberapa konsep antara lain: 1. Konsep Kuantitatif, konsep ini mendasarkan pada kuantitas dari dana yang tertanam dalam unsur-unsur aktiva lancar dimana aktiva ini merupakan aktiva yang sekali berputar kembali dalam bentuk semula atau waktu pendek. 2. Konsep Kualitatif, apabila konsep kuantitatif modal kerja itu hanya dikaitkan dengan besarnya jumlah aktiva lancar saja, maka pada konsep kualitatif ini pengertian modal kerja juga dikaitkan dengan besarnya jumlah utang lancar atau utang lancar yang segera harus dibayar [6]. Sementara itu modal kerja sebagai aktiva lancar yang mewakili bagian dari investasi yang berputar dari satu bentuk ke bentuk lainnya dalam melaksanakan suatu usaha. Dengan kata lain modal kerja diartikan sebagai kas/bank, surat-surat berharga yang mudah diuangkan (misal giro, cek, deposito), piutang dagang dan persediaan yang 
tingkat perputarannya tidak melebihi satu tahun atau jangka waktu operasi normal perusahaan [7].

PT Indofood CBP Sukses Makmur, Tbk merupakan salah satu perusahaan yang bergerak dalam sektor makanan dan minuman yang terdaftar diBursa Efek Indonesia. Beberapa tahun belakangan ini PT Indofood CBP Sukses Makmur Tbk mengalami perkembangan yang sangat pesat dalam bisnisnya hingga menjadi salah satu perusahaan yang terdaftar dalam Indeks LQ45. Indeks LQ45 adalah nilai kapitalisasi pasardari 45 saham yang paling likuid dan memiliki nilai kapitalisasi yang besar.

Untuk mencapai dan mempertahankan tingkat kemajuan kinerja perusahaan yang diinginkan, maka PT Indofood CBP Sukses Makmur Tbk memerlukan adanya evaluasi, terutama pada pengelolaan sumber dan penggunaan capital atau modal kerja yang begitu besar di perusahaan tersebut. Penggunaan modal kerja perusahaan dapat diukur dengan menggunakan rasio perputaran modal (working capital turnover) dan membandingkannya dengan ukuran rasio rata-rata dengan industri sejenis [8].

Berdasarkan latar belakang yang telah dijelaskan diatas, maka dapat dirumuskan permasalahan dalam penelitian ini yaitu "Bagaimanakah sumber dan penggunaan modal kerja pada PT. Indofood CBP Sukses Makmur Tbk?” Dengan tujuan penelitian adalah untuk mengetahui bagaimana sumber dan penggunaan modal kerja pada PT. Indofood CBP Sukses Makmur Tbk.

\section{METODE PENELITIAN}

Penelitian ini dilakukan di PT. Indofood CBP Sukses Makmur Tbk. melalui sistem informasi Bursa Efek Indonesia dengan akses langsung di laman resmi BEI di www.idx.co.id. Yang menjadi sampel dalam penelitian ini adalah laporan keuangan neraca dan laporan laba rugi PT. Indofood CBP Sukses Makmur Tbk tahun 2016.

Metode analisis yang digunakan dalam penelitian ini adalah analisis kuantitatif. Analisis data kuantitatif merupakan data penelitian berupa angka-angka dan analisis menggunakan statistik [9]. Metode penelitian dengan pendekatan kuantitatif digunakan dalam penelitian ini karena data yang menjadi objek dalam penelitian ini merupakan data-data kuantitatif yaitu laporan keuangan PT. Indofood CBP Sukses Makmur Tbk tahun 2016. 
Penelitian ini menggunakan teknik analisis data rasio keuangan yang berhubungan dengan penggunaan modal kerja bersih atau net working capital ratio. Dengan menggunakan tiga rasio yang digunakan untuk menganalisis sumber dan penggunaan modal kerja perusahaa. Rasio-rasio tersebut adalah:

1. Working Capital Turnover (Perputaran Modal Kerja) Adalah alat analisis rasio yang digunakan untuk mengukur tingkat efisiensi perusahaan dalam mengelola modal kerja [10]. Rumusnya adalah sebagai berikut :

$$
\text { Working Capital Turnover }=\frac{\text { Penjualan netto }}{\text { Net Working Capiital }}
$$

2. Rasio Total Aktiva Terhadap Modal Kerja Rasio total aktiva terhadap modal kerja mengukur seberapa besar perbandingan total aktiva terhadap sumber modal kerja yang dimiliki oleh perusahaan. Rumusnya adalah sebagai berikut :

Total Assets to Working Net Capital $=\frac{\text { Current Liabilities }}{\text { Net Working Capital }}$

3. Rasio Kewajiban Lancar Terhadap Modal Kerja Rasio kewajiban lancar terhadap modal kerja mengukur seberapa besar perbandingan kewajiban lancar terhadap sumber modal kerja yang dimiliki oleh perusahaan. Rumusnya adalah sebagai berikut :

Current Liabilities to Working Net Capital $=\frac{\text { Current Liabilities }}{\text { Net Working Capital }}$

\section{HASIL DAN PEMBAHASAN}

\section{a. Hasil Penelitian}

Perubahan modal kerja PT. Indofood CBP Sukses Makmur Tbk selama tahun 2015 dan tahun 2016 dapat dilihat pada pos bertambah ataupun berkurang dalam aset lancar dan liabilitas jangka pendek baik secara sendiri-sendiri maupun secara keseluruhan. Dari tabel 3.1 di bawah ini, dapat dilihat bertambahnya modal kerja PT. Indofood CBP Sukses Makmur Tbk sebesar Rp1.142.421.000.000 disebabkan aset lancar lebih besar jika dibandingkan dengan liabilitas jangka pendek. 
Tabel 1. Laporan Perubahan Modal Kerja PT. Indofood CBP

Sukses Makmur Tbk per 31 Desember 2015 - 31 Desember 2016

(Dalam Jutaan Rupiah)

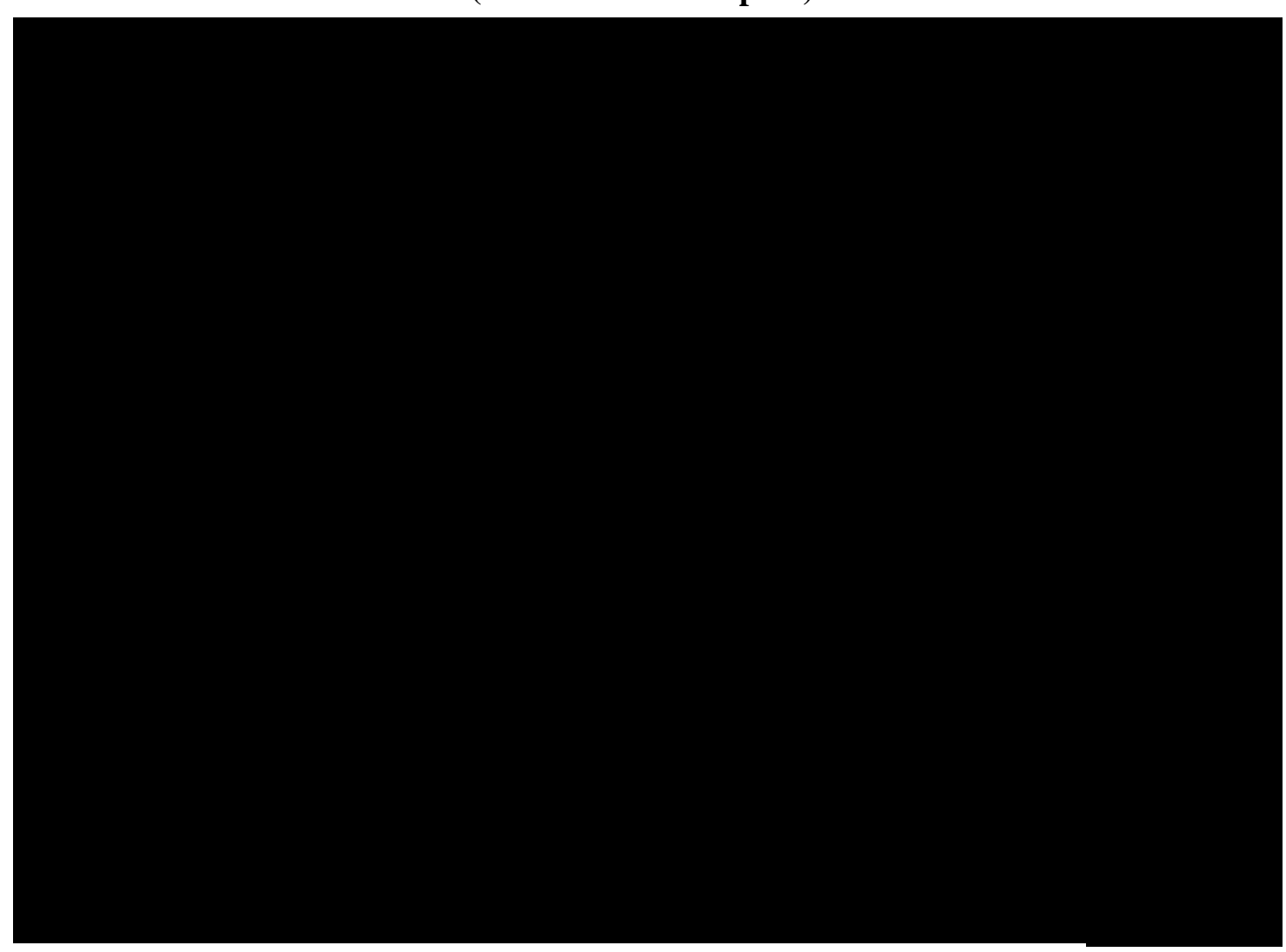

Sumber: Laporan Keuangan PT. Indofood CBP Sukses Makmur

Bertambahnya modal kerja sebesar Rp. 1.142.421.000.000 mengisyaratkan bahwa sumber modal kerja perusahaan tercukupi untuk digunakan dalam operasi perusahaan selama tahun 2016. Kecukupan sumber modal kerja merupakan suatu hal yang sangat penting bagi sebuah perusahaan untuk dapat melaksanakan aktivitasnya, baik untuk bisnis utama perusahaan maupun investasi dan perluasanan pangsa pasar. Selama tahun 2016, PT. Indofood CBP Sukses Makmur Tbk dapat dikatan cukup aman dalam pengendalian sumber dan penggunaan modal kerjanya. Hal ini dibuktikan dengan kenaikan modal kerja yang diikuti dengan peningkatan laba (profit) perusahaan sebesar Rp. 8.825.067.000.000 pada tahun 2015 menjadi Rp. 10.949.473.000.000 pada tahun 2016. Working Capital Turnover atau rasio perputaran modal kerja adalah alat analisis yang digunakan untuk mengukur tingkat efisiensi perusahaan dalam mengelola modal kerja. Rasio perputaran modal kerja PT. 
Indofood CBP Sukses Makmur Tbk. tahun 2016 dapat dihitung (dalam jutaan rupiah) sebagai berikut:

$$
\begin{aligned}
& \text { Working Capital Turnover }=\frac{\text { Penjualan netto }}{\text { Net Working Capital }} \\
& \begin{aligned}
\text { Net Working Capital }=\text { Aktiva Lancar }- \text { Utang Lancar } \\
\text { Net Working Capital }=\mathrm{Rp} 15.571 .362-\mathrm{Rp} 6.469 .785 \\
\text { Net Working Capital }=\mathrm{Rp} 9.101 .577
\end{aligned} \\
& \text { Working Capital Turnover }=\frac{\mathrm{Rp} 34.466 .069}{\mathrm{Rp} 9.101 .577} \\
& \text { Working Capital Turnover }=3,79
\end{aligned}
$$

Dari hasil perhitungan di atas diketahui bahwa rasio perputaran modal kerja atau working capital turnover PT. Indofood CBP Sukses Makmur Tbk. tahun 2016 adalah sebesar 3,79. Rasio perputaran modal kerja PT. Indofood CBP Sukses Makmur Tbk. tahun 2015 dapat dihitung (dalam jutaan rupiah) sebagai berikut:

$$
\text { Working Capital Turnover }=\frac{\text { Penjualan netto }}{\text { Net Working Capital }}
$$

$$
\begin{aligned}
& \text { Net Working Capital }=\text { Aktiva Lancar }- \text { Utang Lancar } \\
& \text { Net Working Capital }=\operatorname{Rp} 13.961 .500-\mathrm{Rp} 6.002 .344 \\
& \text { Net Working Capital }=\mathrm{Rp} 7.959 .156
\end{aligned}
$$

Working Capital Turnover $=\frac{\mathrm{Rp} 31.741 .094}{\mathrm{Rp} 7.959 .156}$

Working Capital Turnover $=3,98$

Dari hasil perhitungan di atas diketahui bahwa rasio perputaran modal kerja atau working capital turnover PT. Indofood CBP Sukses Makmur Tbk. tahun 2015 adalah sebesar 3,98.

Rasio total aktiva terhadap modal kerja mengukur seberapa besar perbandingan total aktiva terhadap sumber modal kerja yang dimiliki oleh perusahaan. Rasio total aktiva terhadap modal kerja PT. Indofood CBP Sukses Makmur Tbk. tahun 2016 dapat dihitung (dalam jutaan rupiah) sebagai berikut:

$$
\text { Total Assets to Working Net Capital }=\frac{\text { Aktiva }}{\text { Net Working Capital }}
$$




$$
\begin{gathered}
\text { Net Working Capital }=\text { Aktiva Lancar }- \text { Utang Lancar } \\
\text { Net Working Capital }=\text { Rp15.571.362 }- \text { Rp6.469.785 } \\
\text { Net Working Capital }=\text { Rp9.101.577 } \\
\text { Total Assets to Working Net Capital }=\frac{\text { Total Aktiva }}{\text { Net Working Capital }} \\
\text { Total Assets to Working Net Capital }=\frac{\text { Rp28.901.948 }}{R p 9.101 .577} \\
\text { Total Assets to Working Net Capital }=3,1
\end{gathered}
$$

Dari hasil perhitungan di atas diketahui bahwa rasio total aktiva terhadap modal kerja PT. Indofood CBP Sukses Makmur Tbk. tahun 2016 adalah sebesar 3,18. Rasio total aktiva terhadap modal kerja PT. Indofood CBP Sukses Makmur Tbk. tahun 2015 dapat dihitung (dalam jutaan rupiah) sebagai berikut:

$$
\begin{aligned}
& \text { Total Assets to Working Net Capital }=\frac{\text { Total Aktiva }}{\text { Net Working Capital }} \\
& \text { Net Working Capital }=\text { Aktiva Lancar }- \text { Utang Lancar } \\
& \text { Net Working Capital }=\text { Rp15.571.362 - Rp6.469.785 } \\
& \text { Net Working Capital }=\text { Rp9.101.577 } \\
& \text { Total Assets to Working Net Capital }=\frac{\text { Total Aktiva }}{\text { Net Working Capital }} \\
& \text { Total Assets to Working Net Capital }=\frac{\mathrm{Rp} 26.560 .624}{R p 9.101 .577}
\end{aligned}
$$

Total Assets to Working Net Capital $=2,91$

Dari hasil perhitungan di atas diketahui bahwa rasio total aktiva terhadap modal kerja PT. Indofood CBP Sukses Makmur Tbk. tahun 2015 adalah sebesar 2,91. Rasio Kewajiban Lancar Terhadap Modal Kerja. Rasio kewajiban lancar terhadap modal kerja mengukur seberapa besar perbandingan kewajiban lancar terhadap sumber modal kerja yang dimiliki oleh perusahaan. Rasio kewajiban lancar terhadap modal kerja PT. Indofood CBP Sukses Makmur Tbk. tahun 2016 dapat dihitung (dalam jutaan rupiah) sebagai berikut:

$$
\begin{aligned}
& \text { Current Liabilities to Working Net Capital }=\frac{\text { Utang Lancar }}{\text { Net Working Capital }} \\
& \qquad \begin{array}{r}
\text { Net Working Capital }=\text { Aktiva Lancar }- \text { Utang Lancar } \\
\text { Net Working Capital }=\text { Rp15.571.362 - Rp6.469.785 }
\end{array}
\end{aligned}
$$




$$
\begin{gathered}
\text { Net Working Capital }=\text { Rp. } 9.101 .577 \\
\text { Current Liabilities to Working Net Capital }=\frac{\text { Utang Lancar }}{\text { Net Working Capital }} \\
\text { Current Liabilities to Working Net Capital }=\frac{\text { Rp6.469.785 }}{R p 9.101 .577} \\
\text { Current Liabilities to Working Net Capital }=0,71
\end{gathered}
$$

Dari hasil perhitungan di atas diketahui bahwa rasio kewajiban lancar terhadap modal kerja PT. Indofood CBP Sukses Makmur Tbk. tahun 2016 adalah sebesar 0,71. Rasio kewajiban lancar terhadap modal kerja PT. Indofood CBP Sukses Makmur Tbk. tahun 2015 dapat dihitung (dalam jutaan rupiah) sebagai berikut:

$$
\begin{aligned}
& \text { Current Liabilities to Working Net Capital }=\frac{\text { Utang Lancar }}{\text { Net Working Capital }} \\
& \begin{array}{r}
\text { Net Working Capital }=\text { Aktiva Lancar }- \text { Utang Lancar } \\
\text { Net Working Capital }=\text { Rp15.571.362 }- \text { Rp6.469.785 } \\
\text { Net Working Capital }=\text { Rp9.101.577 } \\
\text { Current Liabilities to Working Net Capital }=\frac{\text { Utang Lancar }}{\text { Net Working Capital }} \\
\text { Current Liabilities to Working Net Capital }=\frac{\text { Rp6.002.344 }}{\text { Rp9.101.577 }} \\
\text { Current Liabilities to Working Net Capital }=0,65
\end{array}
\end{aligned}
$$

Dari hasil perhitungan di atas diketahui bahwa rasio kewajiban lancar terhadap modal kerja PT. Indofood CBP Sukses Makmur Tbk. tahun 2015 adalah sebesar 0,65.

\section{KESIMPULAN}

Kesimpulan yang dapat diambil adalah secara umum sumber dan penggunaan modal kerja pada PT. Indofood CBP Sukses Makmur Tbk untuk periode 2015 sampai dengan 2016 sudah efesien. Dalam arti bahwa sumber modal kerja yang merupakan tulang punggung operasi perusahaan selalu tersedia dan mengalami kenaikan dari tahun sebelumnya, sehingga kebijakan perusahaan khususnya yang berkaitan dengan operasionalisasi guna mendapatkan laba (profitabilitas) yang optimal dapat dicapai.

Kebijakan penggunaan modal kerja dapat dikatakan sesuai dengan sasaran manajemen. Hal ini terlihat dari peningkatan total asset dan total kewajiban PT. Indofood 
CBP Sukses Makmur Tbk untuk periode 2015 sampai dengan 2016. Artinya, melaui pengadaan kewajiban perusahaan sebagai salah satu sumber modal kerja perusahaan, PT. Indofood CBP Sukses Makmur Tbk mampu menggunakan sumber modal tersebut dengan efisien sehingga mampu menghasilkan kekayaan dalam bentuk aktiva yang berguna bagi jalannya aktivitas bisnis perusahaan selama tahun 2016.

\section{SARAN}

Berikut ini adalah beberapa saran yang dapat diberikan setelah peneliti menganalisis sumber dan penggunaan modal kerjaPT. Indofood CBP Sukses Makmur Tbk tahun 2016: Pihak manajemen PT. Indofood CBP Sukses Makmur Tbk senantiasa memeriksa, mengevaluasi dan mengkaji laporan sumber modal dan penggunaan modal kerja sehingga hal itu dapat menjamin kinerja perusahaan baik dari sisi kebijakan strategis maupun kebijakan keuangan yang semakin baik dimasa mendatang. Sangat diharapkan agar kualitas produk yang baik yang selama ini ditunjukkan selalu dipertahankan agar mendatangkan keuntungan bagi pihak perusahaan sendiri, tetapi juga kepuasan bagi semua konsumen PT. Indofood CBP Sukses Makmur Tbk.

\section{DAFTAR PUSTAKA}

[1] Sutrisno. 2009. Manajemen Keuangan Teori, Konsep, dan Aplikasi. Yogyakarta: Ekonisia, Kampus Fakultas Ekonomi UII.

[2] Irma, Yahya. 2014. Analisis Sumber Dan Penggunaan Modal Kerja Pada PT. Surya Putra Sumetera II Pasir Pengaraian. Jurnal Fakultas Ekonomi Universitas Pasir Pengaraian, Rokan Hulu, Riau. Hal 1-10.

[3] Ghazali, Maswatu. 2015. Analisis Sumber Dan Penggunaan Modal Kerja Pada PT. Bank Tabungan Negara (Persero) Tbk. Cabang Manado. Jurnal Administrasi Bisnis. Hal. 1-12.

[4] Muslich, Mochammad. 2009. Manajemen Keuangan Modern Analisis, Perencanaan dan Kebijaksanaan. Cetakan Ketiga. PT Bumi Aksara. Jakarta.

[5] Agus, Suratinoyo. 2016. Analisa Laporan Sumber-Sumber Dan Penggunaan Modal Kerja Dalam Meningkatkan Profitabilitas Perusahaan Pada PT. Fast Food Tbk. Jurnal Berkala Ilmiah Efisiensi Universitas Sam Ratulangi Manado. Hal 113. 
[6] Made, S.U. dan Made, R. D. S. 2016. Pengaruh Manajemen Modal Kerja terhadap Profitabilitas Perusahaan Manufaktur yang terdaftar di BEI. E-Journal Manajemen Unud.

[7] Veronica. R, Sri Murni dan Ivonne. S. 2016. Analisis Pengaruh Modal Kerja terhadap Profitabilitas pada Industri Telekomunikasi di Indonesia. E-Journal Manajemen Sam Rtulangi.

[8] Yuliastuti.R. 2016. Pengaruh Perputaran Modal Kerja Terhadap Profitabilitas Perusahaan Manufaktur di Bursa Efek Indonesia. E-Journal Manajemen STIESIA.

[9] Sugiyono. 2010. Metode Penelitian Kuantitatif, Kualitatif dan R\&D. Bandung. Alfabeta.

[10] Marzuki. 2012. Metodologi Riset. Yogyakarta: BPFE UII. Madcoms. 2002. Database. 